\title{
Governação de Saúde e Gestão de Proximidade: A Necessidade de Autonomia de Gestão nos Agrupamentos de Centros de Saúde
}

\section{Health Governance and Proximity Management: The Need for Autonomy in Management in Primary Health Care Systems}

\author{
João FIRMINO-MACHADO $\rrbracket^{1,2}$, Inês MAGALHÃES ${ }^{3}$, João RODRIGUES ${ }^{4}$, Victor RAMOS ${ }^{5,6}$, Sofia BAPTISTA ${ }^{1}$, \\ Bernardo VILAS-BOAS ${ }^{3}$
}

Acta Med Port 2017 Jun;30(6):431-433 - https://doi.org/10.20344/amp.8274

Palavras-chave: Administração de Instituições de Saúde; Administração de Serviços de Saúde; Cuidados de Saúde Primários; Governança Clínica; Portugal

Keywords: Clinical Governance; Health Facility Administration; Health Services Administration; Portugal; Primary Health Care

\section{INTRODUÇÃO}

A promoção da saúde, prevenção da doença e os cuidados de proximidade, centrados no utente, sua família e orientados para a comunidade são da responsabilidade dos Cuidados de Saúde Primários (CSP). Em 2006 iniciou-se a transformação gradual dos antigos centros de saúde. A estrutura organizacional de tipo hierárquica e piramidal deu lugar a uma rede de equipas multiprofissionais com caráter estrutural permanente: as unidades de saúde familiar (USF) e outras unidades funcionais (UF). Cada conjunto de UF agregou vários centros de saúde sob a designação de Agrupamentos de Centros de Saúde (ACeS). ${ }^{1-3}$

A aplicação da lei foi limitada. Foi permitida alguma autonomia administrativa aos ACeS. No entanto, a personalidade jurídica e a autonomia financeira, sob a forma de contrato-programa, ficaram retidas nas respetivas Administrações Regionais de Saúde (ARS). O Conselho Executivo do ACeS, com função de aprovar o orçamento-programa, nunca foi criado. A gestão do orçamento, contratação de recursos humanos, definição das entidades prestadoras dos meios complementares de diagnósticos convencionados são da responsabilidade do poder regional. . $^{3,4}$ Esta retenção centralista de capacidades de decisão e gestão limita o potencial de desenvolvimento organizacional, de melhoria da qualidade, bem como a prestação integrada de cuidados.

No panorama internacional, países como Espanha e Reino Unido, em que existe universalidade na prestação de cuidados de saúde, financiados através da coleta de impostos pelo Estado, são dos mais aproximados ao Serviço Nacional de Saúde Português, em termos de CSP. ${ }^{5}$ No caso espanhol, a gestão está descentralizada e é exercida pelas comunidades autónomas, estando os CSP or- ganizados territorialmente. As principais reformas surgiram com a implementação de diversos contratos-programa, que têm permitido aprofundar a autonomia dos profissionais e equipas, descentralizando a gestão. ${ }^{6}$ No Reino Unido o modelo vigente foi lançado em 2014, consistindo em grupos de comissionamento clínico, liderados por médicos de família, e que surgem da noção de que uma solução nacional única pode falhar por não considerar os diferentes contextos locais. ${ }^{7}$

A otimização do modelo organizativo dos CSP em Portugal carece de uma aposta na governação e gestão de proximidade, executadas ao nível dos ACeS. Este processo está previsto desde 2008 em legislação Decreto-Lei (DL) $28 / 2008,{ }^{3}$ no qual estão definidos modelos de contrato-programa ARS-ACeS, com participação das autarquias e assentes no Conselho Executivo do ACeS. O contrato-programa, tal como está descrito no DL, não foi objeto de regulamentação. Para que tal seja possível, é necessário definir o nível de autonomia para os ACeS, bem como estabelecer a articulação entre ARS, ACeS, UF, hospitais, serviços de cuidados continuados e outros serviços.

\section{PROPOSTA DE BASES PARA O CONTRATO-PROGRAMA I - Fundamento \\ A elaboração de bases para o contrato-programa pre- tende conferir maior autonomia aos ACeS. Os autores pro- põem a organização do contrato-programa em áreas fun- damentais baseadas no DL 28/2008 e na reflexão sobre a experiência do desenvolvimento de contratos-programa em Espanha. $^{3,6}$}

\footnotetext{
1. Unidade de Saúde Pública. Agrupamentos de Centros de Saúde Porto Ocidental. Porto. Portugal.

2. Unidade de Investigação em Epidemiologia. Instituto de Saúde Pública. Universidade do Porto. Porto. Portugal.

3. Unidade de Saúde Familiar Serpa Pinto. Agrupamentos de Centros de Saúde Porto Ocidental. Porto. Portugal.

4. Unidade de Saúde Familiar Serra da Lousã. Agrupamentos de Centros de Saúde Pinhal Interior Norte. Lousã. Portugal.

5. Unidade de Saúde Familiar São João do Estoril. Agrupamentos de Centros de Saúde Cascais. Cascais. Portugal.

6. Departamento de Medicina Geral e Familiar. Escola Nacional de Saúde Pública. Lisboa. Portugal.

$\triangle$ Autor correspondente: João Firmino-Machado. firmino.firminomachado@gmail.com

Recebido: 07 de outubro de 2016 - Aceite: 08 de maio de 2017 | Copyright @ Ordem dos Médicos 2017
} 


\section{Ministério da Saúde (MS)}

Administração Central de Serviços de Saúde (ACSS)

Administração Regional de Saúde (ARS)

\section{Agrupamentos de Centros de Saúde (ACeS)}

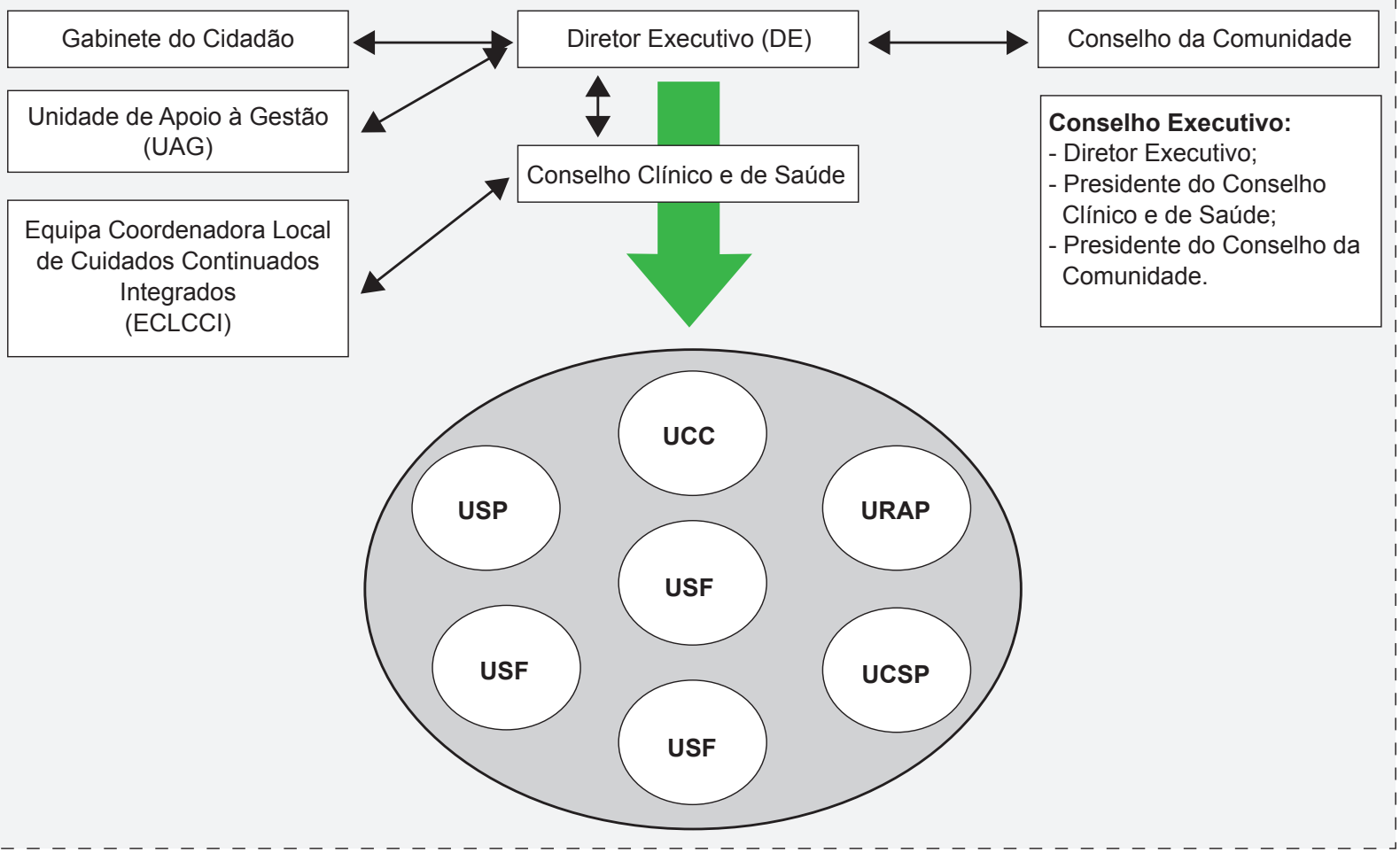

Figura 1 - Modelo organizativo dos cuidados de saúde primários

UCC: Unidade de cuidados continuados; UCSP: Unidade de cuidados de saúde personalizados; URAP: Unidade de recursos assistenciais partilhados; USF: Unidade de saúde familiar; USP: Unidade de saúde pública

Tal permitirá um acompanhamento mais próximo das UF pelos ACeS, garantindo práticas mais seguras, efetivas e de maior qualidade, esperando-se ganhos em saúde, com menor exaustão dos profissionais e maior celeridade na resolução de processos. Este caminho requererá transferência de competências e de responsabilidade das ARS para os ACeS, acompanhada dos respetivos recursos e poder de decisão.

\section{II - Metodologia de trabalho}

Esta reflexão dos autores baseia-se num trabalho desenvolvido pela Associação Nacional das USF. Definiramse quatro eixos fundamentais: Governação Clínica e de Saúde, Recursos Financeiros, Humanos, Direção e Estrutura Integrada. Um documento inicial constituiu a base para grupos de trabalho, de âmbito regional, realizados na área geográfica de três ARS. Participaram diretores executivos, presidentes dos conselhos clínicos e de saúde dos $\mathrm{ACeS}$, elementos das unidades de apoio à gestão e das ARS, médicos e enfermeiros de diversas UF, envolvendo um total de 150 elementos. Nas reuniões regionais foi aplicada a técnica de grupo nominal em que foram produzidos consensos, tendo um grupo coordenador elaborado uma versão final. Esta incorporou, adicionalmente, os contributos dos profissionais presentes no $8^{\circ}$ Encontro Nacional das USF.

\section{III - Conteúdo}

Áreas fundamentais para um contrato-programa:

\section{a) Governação clínica e de saúde}

É uma função central orientadora da atividade do ACeS e das suas UF, para que se promovam elevados padrões de adequação, segurança e efetividade na prestação de serviços de saúde, bem como na melhoria contínua da sua qualidade. Devem ser implementadas práticas baseadas na evidência, monitorizando-se a prescrição de fármacos e de meios complementares de diagnóstico e, ainda, a avaliação por indicadores, escolhidos com base nas efetivas necessidades e prioridades em saúde da população. É prioritária a elaboração de programas de gestão de risco 
clínico e não clínico, a fim de se antecipar e prevenir o erro. É necessário garantir um papel mais ativo dos cidadãos e da comunidade no planeamento em saúde, nomeadamente na identificação de necessidades sentidas, bem como na gestão dos serviços, através da participação dos ACeS nos seus conselhos executivos.

\section{b) Recursos financeiros}

O ACeS deverá ser responsável pela execução orçamental respeitante aos meios técnicos e materiais, bem como a gestão corrente do edificado e infraestruturas. 0 orçamento definido deve ter em consideração os utentes, o contexto geodemográfico e socioeconómico e a sua carga global de doença. Competirá ao ACeS reinvestir as verbas alocadas e não utilizadas por ganhos de eficiência. Este reinvestimento poderá ser feito, por exemplo, em formação e investigação.

\section{c) Recursos humanos}

A tipologia de competências e o número de recursos humanos do ACeS devem estar ajustados à sua população e respetiva carga de doença. Neste sentido, deve também a formação dos profissionais estar centrada nas necessidades do ACeS e no desenvolvimento das diversas equipas das UF, bem como ser alvo de plano anual de formação a definir pelo próprio ACeS. Adicionalmente, os recursos humanos que assumam funções de representação ou participação em grupos de trabalho deverão ter horário laboral que contemple estas mesmas atividades.

\section{d) Direção e estrutura integrada}

A maior autonomia dos ACeS requer uma direção efetiva e alargada, mantendo-se o conselho executivo e o conselho clínico e de saúde, reestruturando os conselhos da comunidade e criando o Conselho de Coordenadores das UF do ACeS. Assim, serão responsáveis pela estratégia e

\section{REFERÊNCIAS}

1. Decreto-Lei n. ${ }^{\circ}$ 24/2006, de 2 de fevereiro. Diário da República: I série, $n^{\circ} 24$. Ministério da Saúde.

2. Decreto-Lei n. ${ }^{\circ}$ 298/2007, de 22 de agosto. Diário da República: I série, n. ${ }^{\circ} 161$. Ministério da Saúde.

3. Decreto-Lei $n .^{\circ}$ 28/2008, de 22 de fevereiro. Diário da República: I série, $\mathrm{n}^{\circ} 38$. Ministério da Saúde.

4. Decreto-Lei $n .^{\circ} 124 / 2011$ de 29 de dezembro. Diário da República: I série, $\mathrm{n}^{\circ} 249$. Ministério da Saúde.

5. Wallace LS. A view of healthcare around the world. Ann Fam Med. 2013;11:84.

6. Aguirre, JG. Contrato de gestión. Instituto Nacional de la Salud (INSALUD), Subdirección General de la Atención Primaria. Atención primaria en el INSALUD: 17 años de experiencia. Madrid: INSALUD; plano de ação locais, promotores da integração de cuidados de saúde focada nas pessoas e no seu percurso de vida-saúde-doença, promotores da cooperação e articulação institucional. Tal é possível através de uma estreita articulação entre os órgãos de governação e de gestão de cada ACeS e as suas UF, os cuidados continuados, unidades hospitalares, parceiros da comunidade e a ARS.

\section{CONCLUSÃO FINAL}

Contrariamente ao que foi definido e fundamentado na estratégia da Reforma dos CSP, ${ }^{8-10}$ ficou por concretizar a autonomia dos ACeS, a regulamentação e implementação dos contratos-programa, como previsto no DL 28/2008. A autonomia é indispensável para que se cumpra a sua verdadeira missão, de governação clínica, organizacional e de saúde. A descentralização adequada de capacidades de decisão permitirá maiores ganhos em saúde.

Um Serviço Nacional de Saúde descentralizado e participado é um bem constitucional, um fator de eficiência para a Administração Central e Regional, de qualidade para os CSP, de proximidade para as comunidades e de satisfação para os utentes.

\section{AGRADECIMENTOS}

Os autores agradecem aos intervenientes nos grupos de trabalho e a António Pereira, Carlos Nunes, José Alvarenga, José Carlos Leitão, Maciel Barbosa, Nuno Capela, Rui Medon, Rosário Santos e Sérgio Vinagre.

\section{CONFLITOS DE INTERESSE}

Os autores declaram não terem qualquer conflito de interesse relativamente ao presente artigo.

\section{FONTES DE FINANCIAMENTO}

Os autores declaram que o presente trabalho não teve apoio de subsídios ou bolsas.
2002. p. $480-1$

7. National Health System. Next steps towards primary care cocommissioning. London: NHS; 2014

8. Ministério da Saúde. Missão para os Cuidados de Saúde Primários (2007a). Reforma dos cuidados de saúde primários - Plano estratégico 2007 - 2009. Lisboa: MS; 2007.

9. Ministério da Saúde. Missão para os Cuidados de Saúde Primários (2007b). Proposta para a reconfiguração dos centros de saúde Criação de agrupamentos de centros de saúde. Lisboa: MS; 2007.

10. Gabinete de Análise Económica. Relatório - Modelo de Prestação de Serviços de Suporte Técnico aos Agrupamentos de Centros de Saúde (ACS). Lisboa: NOVA; 2007. 